myoglobin run required 20 minutes to predict 6000 phases using 2000 known reflections.

\section{References}

Arndt, U. W. \& Phillips, D. C. (1961). Acta Cryst. 14, 807.

Barrett, A. N. \& Zwick, M. (1971). Acta Cryst. A27, 6.

Bisvoet, J. M. (1952). Conference on Computing Methods and the Phase Problem in X-ray Crystal Analysis: Penn. State College, U.S.A. p. 84.

Blow, D. M. \& Crick, F. H. C. (1959). Acta Cryst. 12, 794.

Bodo, G., Dintzis, H. M., Kendrew, J. C. \& Wyckoff, H. W. (1959). Proc. Roy. Soc. A 253, 70.

Cochran, W. (1952). Acta Cryst. 5, 65.

Cochran, W. (1955). Acta Cryst. 8, 473.

Coulter, C. L. (1965). J. Mol. Biol. 12, 292.

Coulter C. L., Hawrinson, S. W. \& Friedmann, H. C. (1969). Biochim. Biophys. Acta, 177, 293.

Dickerson, R. E., Kendrew, J. C. \& Strandberg, B. E. (1961). Acta Cryst. 14, 1188.

FloYd, R. (1964). Commun. Assoc. Comp. Mach. 7, 701. GassmanN, J. (1966). Acta Cryst. 21, A6.

Hawkinson, S. W., Coulter, C. L. \& Greaves, M. L. (1970). Proc. Roy. Soc. A318, 143.

HOPPE, W. (1963). Z. Kristallogr. 118, 121.
Hoppe, W. \& Gassmann, J. (1964). Berichte der Bunsengesellshaft. 68, 808.

Hoppe, W. \& Gassmann, J. (1968). Acta Cryst. B24, 97.

Hughes, E. W. (1953). Acta Cryst. 6, 871.

KARLE, J. (1964). In Advanc. Struct. Res. by Diffn. Methods, Vol. I, Ed. R. BRILL, p. 55. New York: Interscience.

KARLE, J. (1966). Acta Cryst. $21,273$.

KARLE, J. (1968). Acta Cryst. B24, 182.

Karle, J. \& Hauptman, H. (1950). Acta Cryst. 3, 181.

Karle, J. \& Hauptman, H. (1953). Acta Cryst. 6, 473.

Karle, J. \& Hauptman, H. (1956). Acta Cryst. 9, 635.

Karle, J. \& Hauptman, H. (1959). Acta Cryst. 12, 404.

Karle, J. \& Karle, I. L. (1966a). Acta Cryst. 21, 849.

Karle, I. L. \& Karle, J. (1966b). Acta Cryst. 21, 860.

Kendrew, J. C. (1963). In Les Prix Nobel 1962, p. 103. Amsterdam: Elsevier.

Kendrew, J. C., Dickerson, R. E., Strandberg, B. E., Hart, R. G., Davies, D. R., Phillips, D. C. \& Shore, V. C. (1960). Nature, Lond. 185, 422.

ReEke, G. N. \& Lipscomb, W. N. (1969). Acta Cryst. B25, 2614.

SAYRE, D. (1952). Acta Cryst. 5, 60.

Sim, G. A. (1959). Acta Cryst. 12, 813.

Sim, G. A. (1960). Acta Cryst. 13, 511.

Simaika, J. B. (1956). Proc. Math. Phys. Soc. Egypt, 5, 113.

Weinzierl, J. E., Eisenberg, D. \& Dickerson, R. E. (1969). Acta Cryst. B 25, 380.

WILson, A. J. C. (1942). Nature, Lond. 150, 152.

Acta Cryst. (1971). B27, 1740

\title{
The Structure of $\beta$-Uranium
}

\author{
By JeRry Donohue and Howard EINSPahr* \\ Department of Chemistry and Laboratory for Research on the Structure of Matter, University of \\ Pennsylvania, Philadelphia, Pensylvania 19104, U.S.A.
}

(Received 10 August 1970)

\begin{abstract}
During a review of the various structures of uranium, one of us discovered indexing errors that affected a number of the investigations of the $\beta$ allotrope. These errors have been corrected, and least-squares refinements performed in the three possible space groups, $P 4_{2} / m n m, P 4_{2} n m$, and $P \overline{4} n 2$, with resulting $R_{I}$ values of $0.28,0.24$, and 0.28 , respectively. It is concluded that the $\beta$-uranium powder data (Thewlis, 1952) cannot be used to determine the correct space group.
\end{abstract}

$\beta$-Uranium, the allotrope stable between $661^{\circ}$ and $772^{\circ} \mathrm{C}$, has been subject of repeated structural investigations for over 20 years. Great experimental difficulties are encountered in obtaining intensity data, owing to the excessive reactivity of the metal and to the inability of the allotrope to retain its structure on quenching.

Tucker (1951), using $\mathrm{Cu} K \alpha$ radiation, obtained projection data at room temperature from a single

* Present address: A. A. Noyes Laboratories of Chemical Physics, California Institute of Technology, Pasadena, California 91109, U.S.A. crystal of a 1.4 atomic $\% \mathrm{Cr}$ alloy of uranium that had been quenched from above the transition temperature with no evidence of reformation of the $\alpha$ allotrope. The lattice was found to be tetragonal with $a=10 \cdot 52, c=5 \cdot 57 \AA$, and $Z=30$. Systematic absences $(0 k l, \quad k+l=2 n+1)$ admitted three possible space groups: the centrosymmetric $P 4_{2} / \mathrm{mnm}$, and the noncentrosymmetric $P 4_{2} n m$ and $P \overline{4} n 2$. A structure was proposed in $P 4_{2} \mathrm{~nm}$ based on Patterson projections using $0 \mathrm{kl}$ and $h k 0$ data. No refinement was reported. $P 4_{2} / m n m$ was judged less favorable on the basis of detailed intensity considerations; $P \overline{4} n 2$ was not considered.

Thewlis (1952) published a powder pattern of $\beta$ - 
uranium obtained at $720^{\circ} \mathrm{C}$ and indexed on a tetragonal lattice with $a=10 \cdot 759(1)$ and $c=5 \cdot 656(1) \AA$. Intensities were estimated with a microphotometer and corrected for absorption. As indexed by Thewlis, 40 of the 71 lines for which intensity measurements were made were resolved. Thewlis compared this pattern with that of a 1.4 atomic $\% \mathrm{Cr}$ alloy pattern obtained by him and raised doubts about the identity of the alloy and $\beta$-uranium structures.

Tucker \& Senio (1953), hereinafter referred to as TS(1), refined, by means of successive Fourier syntheses, models in space groups $P 4_{2} \mathrm{~nm}$ and $P 4_{2} / \mathrm{mnm}$ using new and improved single-crystal $h k 0$ and $0 \mathrm{kl}$ data for the alloy. In this case, the centrosymmetric structure was favored by the authors on the basis of overall intensity agreement, especially for moderate and weak reflections. Comparison of these data with those of pure uranium powder (Thewlis, 1952) did not produce the marked discrepancies noted by Thewlis in his alloy pattern. Further, it was reported that decreasing the chromium content in a series of alloys from 4 to 0.3 atomic $\%$ produced no significant changes in intensities.

Thewlis \& Steeple (1954), hereinafter referred to as TS(2), published refinements of both models of TS(1) using 36 resolved reflections from the powder pattern of Thewlis. Four reflections were excluded from the initial set of 40 because of contamination with oxide lines. The method of refinement was an unpublished one, wherein each parameter shift was chosen to minimize independently the function $\sum|| F_{o}|-| F_{c}||$. Some correlation between parameters was apparently permitted in later cycles by introducing partial derivatives. The model based on $\mathrm{P4}_{2} \mathrm{~nm}$ with 13 parameters refined to an $R$ of $0 \cdot 19$ over both resolved and unresolved data; the centrosymmetric model with 8 parameters refined to a corresponding $R$ of $0 \cdot 32$. It was concluded by $\operatorname{TS}(2)$ that the noncentrosymmetric structure was the correct one.

Later, the principals in the controversy (Tucker, Senio, Thewlis \& Steeple, 1956) published a joint note comparing their results and, in the absence of concordance, agreed to disagree on the structure of $\beta$-uranium.

Finally, Steeple \& Ashworth (1966), hereinafter referred to as SA, published additional refinement of these two models using, once again, the powder data of Thewlis (1952). The method of refinement was a computerized version of the one used by TS(2), but it was expanded to include multiple or unresolved reflections and to permit parameter shifts along the diagonals of the unit cell for refining coordinates of the type $(x, x, z)$. The function minimized was the $R V_{1}$ factor, $\sum|| V I_{o}|-| V I_{c}|| / \sum\left|V I_{o}\right|$, where $I_{c}=\sum p_{i} F_{c}^{2}(i)$ and $p_{i}$ is the multiplicity of the $i$ th unresolved reflection. The overall isotropic thermal parameter was set at $1.0 \AA^{2}$ and 65 intensity data were used. The $R_{V_{1}}$ value for the centrosymmetric model was 0.23 and that for the noncentrosymmetric model was $0 \cdot 16$. The latter model was judged by the authors to be the more likely one.

Table 1. Corrected indexing of the $\beta$-uranium powder pattern (Thewlis, 1952)

Lines are numbered as in Thewlis (1952). Previously omitted, accidentally coincident reflections have indices singly underscored; omitted Pythagorean multiples coincident with Thewlis assignments have indices doubly underscored.

\begin{tabular}{|c|c|c|c|c|c|c|c|}
\hline & dobs, $\mathscr{A}$ & hike & dcalc, $\dot{A}$ & & & & \\
\hline 20. & 1.526 & $\begin{array}{r}413 \\
550.710 \\
\end{array}$ & $\begin{array}{l}1.528 \\
1.522\end{array}$ & 55. & .9211 & $\begin{array}{r}10.2 .3 \\
11.1 .2 \\
\end{array}$ & $\begin{array}{r}.9207 \\
.9210\end{array}$ \\
\hline 27. & 1.415 & $\begin{array}{r}004 \\
730 \\
433,503 \\
\end{array}$ & $\begin{array}{l}1.414 \\
3.413 \\
1.418\end{array}$ & 56. & .9184 & $\begin{array}{c}844 \\
11.4 .0 \\
\end{array}$ & $\begin{array}{r}.9162 \\
.9192\end{array}$ \\
\hline & 1.184 & $\begin{array}{c}553,713 \\
822 \\
434 \\
\frac{410}{910}\end{array}$ & $\begin{array}{l}1.184 \\
1.185 \\
1.182 \\
1.188\end{array}$ & 57. & .9107 & $\begin{array}{c}705 \\
10.6 .1 \\
10.5 .2 \\
11.2 .2 \\
\end{array}$ & $\begin{array}{r}0.9111 \\
.9105 \\
.9110\end{array}$ \\
\hline & 1.177 & $\begin{array}{l}841 \\
514 \\
\end{array}$ & $\begin{array}{l}1.177 \\
1.175\end{array}$ & 58. & .9010 & $\begin{array}{r}645 \\
882 \\
764.924 \\
\end{array}$ & $\begin{array}{l}.9014 \\
.9014 \\
.9000\end{array}$ \\
\hline 38. & 1.116 & $\begin{array}{l}851 \\
115 \\
\end{array}$ & $\begin{array}{l}1.118 \\
1.119\end{array}$ & 59. & .8954 & $\begin{array}{r}972 \\
11.3 .2 \\
\end{array}$ & .8951 \\
\hline 39. & $1.079 \%$ & $\begin{array}{c}305 \\
762,922 \\
544 \\
\end{array}$ & $\begin{array}{l}1.079 \\
1.079 \\
1.082\end{array}$ & 62. & .8598 & $\begin{array}{r}516 \\
12.3 .1 \\
\end{array}$ & $\begin{array}{l}.8607 \\
.8597\end{array}$ \\
\hline & & $\underline{860}, \underline{10.0 .0}$ & 1.076 & 63. & .8571 & $\begin{array}{c}864,10.0 .4 \\
10.5 .3 \\
11.2 .3 \\
\end{array}$ & $\begin{array}{l}.8562 \\
.8571\end{array}$ \\
\hline & $1.073^{* 4}$ & $\begin{array}{r}315 \\
823 \\
941 \\
10.1 .0 \\
\end{array}$ & $\begin{array}{l}1.073 \\
1.073 \\
1.073 \\
1.071\end{array}$ & 64. & .8546 & $\begin{array}{c}825 \\
10.1 .4 \\
12.0 .2 \\
\end{array}$ & $\begin{array}{l}.8547 \\
.8535 \\
.8547\end{array}$ \\
\hline 41. & 1.051 & $\begin{array}{c}663 \\
932 \\
10.1 .1 \\
833\end{array}$ & $\begin{array}{l}1.052 \\
1.053 \\
1.052 \\
1.047\end{array}$ & 65. & .8521 & $\begin{array}{r}526 \\
982 \\
12.1,2 \\
\end{array}$ & $\begin{array}{l}.8525 \\
.8520\end{array}$ \\
\hline 44. & 1.022 & $\begin{array}{l}724 \\
425 \\
942 \\
\end{array}$ & $\begin{array}{l}1.022 \\
1.024 \\
1.019\end{array}$ & 72. & $.8020 \%$ & $\begin{array}{l}556.716 \\
\frac{935}{11.1 .4} \\
\frac{12.6 .0}{12.0}\end{array}$ & $\begin{array}{l}.8013 \\
.8009 \\
.8022 \\
.8019\end{array}$ \\
\hline 49. & 0.9742 & $\begin{array}{r}804 \\
11.1 .0 \\
\end{array}$ & $\begin{array}{r}0.9745 \\
.9741\end{array}$ & 73. & $.7953^{*}$ & $\begin{array}{c}726 \\
10.5 .4 \\
11.2 .4 \\
\end{array}$ & $\begin{array}{l}.7948 \\
.7956\end{array}$ \\
\hline 50. & .9621 & $\begin{array}{l}10.5 .0 \\
11.2 .0 \\
\end{array}$ & .96 .73 & & & $\underline{12.5 .2}$ & .7943 \\
\hline 51. & .9489 & $\begin{array}{l}10.5 .1 \\
11.2 .1 \\
\end{array}$ & .9487 & & & & \\
\hline 52. & .9442 & $\begin{array}{r}664 \\
970 \\
11.3 .0 \\
\end{array}$ & $\begin{array}{l}.9440 \\
.9436\end{array}$ & & & & \\
\hline
\end{tabular}

* Lines 39 and 40 were omitted from these refinements because of ambiguity in assignment of omitted, accidentally coincident reflections. Lines 72 and 73 were omitted because of uncertainty in the empirical absorption - LP correction.

During a review of this subject by one of us, it was discovered that a number of coincident reflections of the Pythagorean kind had been overlooked by Thewlis in indexing the pure uranium powder pattern. A program was written to generate the indices and interplanar spacings of all reflections permitted by the extinction conditions throughout the range of observation reported for this pattern. The results, shown in Table 1, indicated that Thewlis had ignored a significant number of coincidences, both Pythagorean and accidental. This incomplete indexing had been used 
in all refinements of the powder data; e.g., among the 65 lines used by SA, 34 coincident reflections had been overlooked. The omissions affected 24 lines, 11 of them previously considered resolved. Structure-factor calculations using both models of SA attributed significant intensities to many of these reflections. Consequently, we decided to undertake a new refinement with the revised indexing.

The full-matrix least-squares program UCLALS4 (Gantzel, Sparks, Long \& Trueblood, 1964) was modified to handle coincident reflections and to refine an overall isotropic thermal parameter. The function minimized is $\sum w\left(I_{o}-I_{c}\right)^{2}$, where $w$ is the weight assigned the observation $I_{o}$, and $I_{c}$ is defined above.

Since the data tables for the powder pattern (wherever published) were back-corrected for absorption, Lorentz and polarization effects, these corrections had to be made empirically. To this end, an $F^{2}$ calculation was made under conditions duplicating those of SA using their $\mathrm{P4}_{2} \mathrm{~nm}$ model. The $F^{2}$ values were corrected for multiplicity and summed to account for coincidences wherever indicated by the indexing of Thewlis. Ratios of these intensities and the published, calculated intensities of SA were plotted versus the interplanar spacings. Corrections for individual lines were read from a smooth curve drawn through the points on the graph.

Four lines were omitted from the refinements that followed because of ambiguities regarding the assignment of omitted, accidentally coincident reflections or uncertainties in the absorption-LP correction at the tail of the correction curve. A total of 61 intensity observations remained, of which 25 were resolved. For want of a better scheme, each observation was given unit weight. The scattering factor used was that of Pauling \& Sherman (1932).

Table 2. Refinement in $P 4_{2} / \mathrm{mnm}$

$\begin{array}{ccccc}\begin{array}{c}\text { Atom } \\ \text { type }\end{array} & & \text { TS(1) } & \begin{array}{c}\text { This } \\ \text { refinement }\end{array} & \text { SA } \\ \text { II } & x & 0.103 & 0.099 & 0.098 \\ \text { III } & x & 0.318 & 0.316 & 0.321 \\ & z & 0.270 & 0.280 & 0.277 \\ \text { IV } & x & 0.561 & 0.556 & 0.561 \\ & y & 0.235 & 0.228 & 0.214 \\ \text { V } & x & 0.367 & 0.368 & 0.370 \\ & y & 0.038 & 0.039 & 0.046 \\ & B & - & 1.81 \AA^{2} & 1.0 \AA^{2}\end{array}$

Refinements in $\mathrm{PH}_{2} / \mathrm{mnm}$ were made using both the original TS(1) and refined SA coordinates as starting models. Nine parameters were refined, including the overall isotropic thermal parameter and scale factor. Both refinements converged to the same final model. Coordinates of the refined model, together with those of the starting models, are shown in Table 2. The final $R_{I}$, defined as $\sum\left|I_{o}-I_{c}\right| / \sum I_{o}$, was $0 \cdot 28$; the final weighted $R_{I}$, defined as $\left[\sum w\left(I_{o}-I_{c}\right)^{2} / \sum w I_{o}^{2}\right]^{\frac{1}{2}}$, was $0 \cdot 30$.
To check the validity of the weighting scheme, a graph of the differences between observed and calculated intensities versus the observed values was plotted. Scatter among the points was high, and no systematic relationship could be discerned from this plot.

Both the Tucker (1951) and SA models were used as starting sets for the $\mathrm{P4}_{2} \mathrm{~nm}$ case with 14 parameters to be refined. Both refinements converged toward essentially the same model; all final shifts were less than $5 \%$ of the corresponding estimated standard deviations. Coordinates of the final model, together with those of the starting models, are shown in Table 3. The final $R_{I}$ was $0 \cdot 24$; the final weighted $R_{I}$ was 0.26 .

Table 3. Refinement in $\mathrm{PH}_{2} \mathrm{~nm}$

\begin{tabular}{ccccr}
$\begin{array}{c}\text { Atom } \\
\text { type }\end{array}$ & & \multicolumn{3}{c}{$\begin{array}{c}\text { This } \\
\text { Tucker (1951) }\end{array}$} \\
I & $z$ & 0.50 & 0.500 & \multicolumn{1}{c}{ SA } \\
II & $x$ & 0.500 \\
& $z$ & 0.07 & 0.107 & 0.110 \\
III $a$ & $x$ & 0.32 & 0.014 & -0.017 \\
& $z$ & 0.84 & 0.769 & 0.301 \\
III $b$ & $x$ & 0.32 & 0.321 & 0.315 \\
& $z$ & 0.34 & 0.294 & 0.280 \\
IV & $x$ & 0.56 & 0.558 & 0.563 \\
& $y$ & 0.24 & 0.225 & 0.220 \\
& $z$ & 0.09 & 0.052 & 0.075 \\
V & $x$ & 0.38 & 0.372 & 0.374 \\
& $y$ & 0.04 & 0.045 & 0.042 \\
& $z$ & 0.04 & -0.023 & -0.026 \\
& $B$ & - & $1.28 \AA^{2}$ & $1.0 \AA^{2}$
\end{tabular}

Attention was now turned to space group $P \overline{4} n 2$. Random shifts were applied to the previously refined centrosymmetric model, and the resulting coordinates were used as the starting model. Refinement with 12 parameters was ended under conditions similar to those of the $P 4_{2} \mathrm{~nm}$ refinement with a final $R_{I}$ of 0.28 .

It should be pointed out that the starting models used in both noncentrosymmetric refinements were sufficient departures from centrosymmetry to obviate the catastrophic results warned against by Ermer \& Dunitz (1970). Further, a permutation of the random shifts used to construct the starting model for the $P \overline{4} n 2$ case refined to the same model, except for a change of origin. While this is by no means an exhaustive survey of the possibilities, we doubt that any permutation of the shifts that remains untested would lead to a significantly better model.

Coordinates for the refined models in the three space groups are shown in Table 4. Coordinates of the $P \overline{4} n 2$ model have been referred to a non-standard origin at $\left(\frac{1}{2}, 0, \frac{1}{4}\right)$ for comparison purposes. While standard deviations were obtained for these parameters in the usual manner; they were considered of doubtful significance in view of the uncertainty in the correct model; a representative value for positional parameters is 0.004 . The models are not strikingly different; 
the chief difference is in the $z$ coordinates of the last two atoms in each set. This difference produces the rumpling of the main layers in the two noncentrosymmetric models noted by the previous investigators for the $P 4_{2} n m$ case.

Table 4. Comparison of refinements

\begin{tabular}{|c|c|c|c|c|c|}
\hline $\begin{array}{l}\text { Atom } \\
\text { type }\end{array}$ & & $P 4_{2} / \mathrm{mnm}^{*}$ & $P \overline{4} n 2 \dagger$ & & $n m t$ \\
\hline I & $x$ & 0 & 0 & & 0 \\
\hline & $y$ & 0 & 0 & & \\
\hline & $z$ & $\frac{1}{2}$ & $\frac{1}{2}$ & & 0.500 \\
\hline II & $x$ & 0.099 & $0 \cdot 100$ & & $0 \cdot 107$ \\
\hline & $y$ & 0.099 & 0.100 & & 0.107 \\
\hline & $z$ & 0 & 0 & & -0.014 \\
\hline & & & & $a$ & $b$ \\
\hline III & $x$ & 0.313 & $0 \cdot 313$ & 0.303 & 0.321 \\
\hline & $y$ & 0.316 & 0.323 & 0.303 & 0.321 \\
\hline & $z$ & $0 \cdot 280$ & $0 \cdot 275$ & 0.769 & 0.294 \\
\hline IV & $x$ & 0.556 & 0.557 & & 0.558 \\
\hline & $y$ & 0.228 & 0.228 & & 0.225 \\
\hline & $z$ & 0 & 0.043 & & 0.052 \\
\hline V & $x$ & $0 \cdot 368$ & $0 \cdot 368$ & & 0.372 \\
\hline & $y$ & 0.039 & 0.041 & & 0.045 \\
\hline & $z$ & & -0.017 & & -0.023 \\
\hline & $B$ & $1 \cdot 81 \AA^{2}$ & $1.56 \AA^{2}$ & & $1 \cdot 28 \AA^{2}$ \\
\hline & $\begin{array}{l}\text { Degrees of } \\
\text { freedom }\end{array}$ & 9 & 12 & & 14 \\
\hline & $R_{I}$ & 0.28 & $0 \cdot 28$ & & 0.24 \\
\hline & $w R_{I}$ & $0 \cdot 30$ & 0.28 & & 0.26 \\
\hline
\end{tabular}

* In this space group $x(\mathrm{I})=0, y(\mathrm{I})=0, z(\mathrm{I})=\frac{1}{2}, x(\mathrm{II})=y(\mathrm{II})$, $z(\mathrm{II})=0, x(\mathrm{III})=y(\mathrm{III}), z(\mathrm{IV})=0$, and $z(\mathrm{VI})=0$.

$\dagger$ In this space group $x(\mathrm{I})=0, y(\mathrm{I})=0, z=\frac{1}{2}, x(\mathrm{II})=y(\mathrm{II})$, and $z(\mathrm{II})=0$.

\pm In this space group $x(\mathrm{I})=0, y(\mathrm{I})=0, z(\mathrm{I})=\frac{1}{2}$ (arbitrarily fixed), and $x(\mathrm{III} a, b)=y(\operatorname{III} a, b)$, respectively, two sets of special positions $4(c)$ being needed to describe the spatial distribution of atom type III.

Another feature of these models, also noted by previous investigators, is a short interatomic distance produced by the third atom of each model (Table 4).
In the $P 4_{2} / m n m$ case, the distance from this atom to the one directly above it at $(x, x, 1-z)$ is $2.49 \AA$, all other interatomic distances being $2.9 \AA$ or greater. In the $P \overline{4} n 2$ model this distance is $2.55 \AA$ and in the $P 4_{2} \mathrm{~nm}$ model it is $2.70 \AA$. However, in the latter case, there is a $2.63 \AA$ distance, also previously noted, between atoms in successive main layers and almost directly above one another in $z$. The shortest distance observed in either the $\alpha$ or $\gamma$ phase of uranium is 2.76 $\AA$, according to TS(1).

No result of this investigation pointed to one of these models as the correct one. The present $\beta$-uranium powder data show no significant preference for any one of these models.

No refinement has been reported using the threedimensional single-crystal data of TS(1). Although absorption corrections were reported to have been made for these data, comparison of the intensities of equivalent reflections suggests that significant absorption errors remain in the data (Tucker et al., 1956). Apparently, in order to settle the ambiguities regarding the $\beta$-uranium structure, improved data must be collected.

This work was supported by the National Science Foundation and the Advanced Research Projects Agency, Office of the Secretary of Defense.

\section{References}

Ermer, O. \& Dunitz, J. D. (1970). Acta Cryst. A 26, 163.

Gantzel, P. K., Sparks, R. A., Long, R. E. \& Trueblood, K. N. (1964). Unpublished work.

Pauling, L. \& Sherman, J. (1932). Z. Kristallogr. 81, 1.

Steeple, H. \& Ashworth, T. (1966). Acta Cryst. 21, 995. Thewlis, J. (1952). Acta Cryst. 5, 790.

Thewlis, J. \& Steeple, H. (1954). Acta Cryst. 7, 323.

TuCKer, C. W., JR (1951). Acta Cryst. 4, 425.

TuCKer, C. W., JR \& Senio, P. (1953). Acta Cryst. 6, 753. Tucker, C. W., Jr, Senio, P, Thewlis, J. \& Steeple, H. (1956). Acta Cryst. 9, 472. 